\title{
0 cuidador no provimento do cuidado ao paciente com câncer avançado no Instituto Nacional de Câncer ${ }^{1}$
}

\author{
Caregivers of Advanced Cancer Patients at the Brazilian National Cancer \\ Institute
}

Autora: Ana Raquel de Mello Chaves $^{2}$

Orientadora: Dra. Ana Maria de Vasconcelos 3

\begin{abstract}
Este estudo objetivou identificar e analisar o perfil, as condições de inserção e a participação do cuidador junto ao paciente com câncer avançado, na conjuntura atual, atendidos no Instituto N acional de Câncer (INCA), possibilitando, assim, contribuir para a discussão a respeito desta temática nessa instituição e na área da saúde. Esta pesquisa foi realizada com 25 cuidadores, no período de agosto de 2003 a janeiro de 2004, no setor de Internação Hospitalar do H ospital do Câncer IV, do IN CA, no Rio de Janeiro, por ser um centro formador de políticas públicas de saúde em cuidados paliativos no Brasil. U tilizaram-se como metodologia as abordagens quantitativa e qualitativa - através de revisão bibliográfica, observação participante e entrevista com os cuidadores dos pacientes com câncer avançado - sendo a matriz teórico-metodológica da totalidade escolhida por permitir inserir a discussão no contexto mais geral da sociedade brasileira. Como resultados, essa pesquisa demonstrou que os cuidadores são em sua maioria familiares (92\%) e do sexo feminino (96\%), havendo apenas $4 \%$ de cuidadores do sexo masculino; em idade laborativa (64\%) e que residem com o paciente (68\%). Além disso, há um percentual representativo de cuidadores (36\%) que permanecem no mercado de trabalho (formal ou informal, sendo que desses 78\% com renda de 1 a 2 salários mínimos), como também de cuidadores que deixaram de trabalhar para efetivarem os cuidados ao paciente (32\%), o que configura dificuldades financeiras. 0 grau de instrução dos cuidadores entrevistados se apresentou diverso, sendo importante ressaltar o quantitativo de cuidadores com ensino médio (32\%) e a presença de cuidadores de nível superior (4\%). Além disso, o estudo evidenciou que os cuidadores assumem a responsabilidade pelos cuidados (92\%), sendo, por vezes, os únicos cuidadores ou de maior tempo disponível, sendo motivados pelo afeto $(60 \%)$ e solidariedade $(12 \%)$ ao paciente, como também pela necessidade apresentada pelo paciente devido à condição clínica (24\%). Vale ressaltar que o cuidado ocorre mesmo que os cuidadores estejam em sofrimento por conviver com o processo de doença avançada e de terminalidade de vida de seu familiar/paciente (88\%), ou seja, mesmo com o conhecimento da possibilidade de perda de seu ente enfermo. O s cuidadores se apresentam como sujeitos que, ao cuidar do paciente com câncer avançado, apresentam alterações no seu cotidiano, tais como: cansaço físico (44\%), emocional (76\%), estresse $(40 \%)$ e problemas de saúde (28\%). Assim, observou-se que o adoecimento de um membro da família altera o cotidiano, principalmente daquele que centraliza os cuidados, pois é comum o cuidador abdicar de suas atividades (como lazer e emprego) para se dedicar à tarefa de cuidar.
\end{abstract}

\footnotetext{
${ }_{1}^{1}$ D issertação apresentada ao Programa de Pós-graduação da Faculdade de Serviço Social da Universidade do Estado do Rio de Janeiro para obtenção do título de M estre em Serviço Social. Rio de Janeiro, 2004.

${ }^{2}$ Assistente Social do setor de Internação D omiciliar do H ospital de Câncer IV do Instituto N acional de Câncer; Especialista em Serviço Social em Oncologia; M estre em Serviço Social.

${ }^{3}$ D outora em Serviço Social; D ocente da Faculdade de Serviço Social da Universidade do Estado do Rio de Janeiro.

Endereço para correspondência: H ospital do Câncer IV -Serviço Social - Rua Visconde de Santa Isabel no 274 - Vila Isabel - Rio de Janeiro/RJ -

Cep: 20560-120. E-mail: ra.chaves@globo.com
} 